\title{
Injuries in Elite Men's Rugby Union: An Updated (2012-2020) Meta-Analysis of 11,620 Match and Training Injuries
}

\author{
Sean Williams $^{1}$ (D) $\cdot$ Charli Robertson $^{1} \cdot$ Lindsay Starling $^{1}$ (D) $\cdot$ Carly McKay $^{1}$ (D) Stephen West $^{2,3}$ (D) James Brown J $^{4,6}$. \\ Keith Stokes ${ }^{1,5}$
}

Accepted: 11 November 2021 / Published online: 2 December 2021

(c) The Author(s) 2021

\begin{abstract}
Background The most recent meta-analytic review of injuries in elite senior men's Rugby Union was published in 2013. The demands of the game at the elite level are continually changing alongside law amendments and developments in player preparation. As such, an updated meta-analysis of injury data in this setting is necessary.

Objective To meta-analyse time-loss injury data in elite senior men's Rugby Union between 2012 and 2020.

Methods Electronic databases were searched using the keywords 'rugby' and 'inj*'. Nineteen studies met the inclusion criteria. Injury incidence rate data were modelled using a mixed-effects Poisson regression model. Days missed data were modelled using a general linear mixed model.

Results The included data encompassed a total of 8819 match injuries and 2801 training injuries. The overall incidence rate of injuries in matches was 91 per $1000 \mathrm{~h}$ (95\% confidence interval (CI) 77-106). The estimated mean days missed per match injury was 27 days (95\% CI 23-32). The overall incidence rate of match concussions was 12 per $1000 \mathrm{~h}$ (95\% CI 9-15). The overall incidence rate of training injuries was 2.8 per $1000 \mathrm{~h}$ (95\% CI 1.9-4.0). Playing level was not a significant effect modifier for any outcome.

Conclusions The injury incidence rate and mean days missed per injury in the present meta-analysis were higher, but statistically equivalent to, the 2013 meta-analysis ( 81 per $1000 \mathrm{~h}$ and 20 days, respectively). The injury incidence rate for match injuries in elite senior men's Rugby Union is high in comparison to most team sports, though the training injury incidence rate compares favourably. The tackle event and concussion injuries should continue to be the focus of future preventative efforts.
\end{abstract}

Sean Williams

S.Williams@bath.ac.uk

1 Centre for Health and Injury and Illness Prevention in Sport, Department for Health, University of Bath, Bath BA2 7AY, UK

2 Faculty of Kinesiology, Sport Injury Prevention Research Centre, University of Calgary, Calgary, Canada

3 O'Brien Institute for Public Health, University of Calgary, Calgary, Canada

4 Division of Orthopaedic Surgery, Department of Surgical Sciences, Faculty of Medicine and Health Sciences, Institute of Sport and Exercise Medicine, Stellenbosch University, Stellenbosch, South Africa

5 Rugby Football Union, Twickenham, UK

6 IOC Research Centre, Pretoria, South Africa

\section{Key Points}

The incidence rate for match injuries in elite senior men's Rugby Union is high in comparison to most team sports (91 per $1000 \mathrm{~h}$ ), though the training injury incidence rate compares favourably ( 2.8 per $1000 \mathrm{~h}$ ).

The mean days missed per match injury was 27 days.

Playing level was not a significant effect modifier for any injury outcome.

The tackle event and concussion injuries should continue to be the focus of future preventative efforts. 


\section{Introduction}

Rugby Union is amongst the most played and watched sports in the world, with approximately 9.6 million registered players in over 123 countries [1]. The game is physically demanding, with bouts of walking, jogging and running, interspersed with sprinting, static exertions and contact events [2]. Moreover, the demands of the game at the elite level are continually changing alongside law amendments [3] and developments in match analysis, equipment, technology and player training [4]. The most recent meta-analytic review of injuries in elite senior men's Rugby Union was published in 2013 [5]. This metaanalysis confirmed that match injury incidence rates in elite senior men's Rugby Union can be considered high in comparison to other team sports (overall injury incidence rate: 81 per $1000 \mathrm{~h}$ ), but similar to other collision-based sports [5]. It was recommended that injury prevention efforts should target lower-limb injury prevention strategies and technique during contact to reduce the burden of injury in the sport.

Since the publication of the most recent meta-analysis in 2013, efforts to reduce injury risk in elite senior men's Rugby Union have been undertaken [6, 7], primarily in response to rapidly increasing rates of concussion injuries [8]. These increases are thought to be due, in part, to the introduction of processes to better identify and manage head impact events during matches [9] as well as increased awareness and education around concussions. However, a real change in concussion risk resulting from changes to the demands of the elite game is also likely. Concern about potential long-term problems associated with concussion and/or multiple head impacts (i.e., neurodegenerative diseases) is recognised by medical and lay populations [10], and is a prominent issue in elite Rugby Union. Given the changes that have occurred within elite Rugby Union since 2013, and the volume of data published from new and existing injury surveillance projects, there is a clear need for an updated review and meta-analysis of injuries in this population. An updated meta-analysis will provide the most precise and up-to-date estimates of injury risk to best inform future preventative strategies in elite senior men's Rugby Union.

\section{Objective}

The objective of this review is to meta-analyse the epidemiological data of time-loss injuries in elite senior men's Rugby Union between 2012 and 2020, with specific reference to: match injury incidence rates; days missed for match injuries; match concussion incidence rates; and training injury incidence rates. The effect of playing level and position as a moderating factor are also explored. In addition, the proportion of match injuries as a function of injury location and match event are summarised.

\section{Methods}

Guidelines for reporting meta-analysis of observational studies in epidemiology (MOOSE guidelines) [11] were followed, including specifications for reporting background, search strategy, methods, results, discussion and conclusion. Details of the protocol for this systematic review were registered on PROSPERO and can be accessed at: www.crd. york.ac.uk/PROSPERO/display_record.asp?ID=CRD42 020200627.

\subsection{Literature Search}

Web of Science, PubMed and Google Scholar databases were searched (by SWi) from September 2012 through October 2020 using the keywords "rugby" and "inj*". Furthermore, the reference lists of included studies and relevant "grey literature' (e.g., conference proceedings and online annual injury surveillance reports) were searched to identify additional articles. Inclusion criteria for retrieved studies were: (1) prospective cohort studies; (2) study population comprising 15-a-side senior elite male Rugby Union teams; (3) use of a 24-h timeloss injury definition [12]; (4) full-text version available in English; (5) data pertaining to 2012 onwards; and (6) reports injury incidence rates for one or more of the following epidemiological data: (1) match or training injuries; (2) match concussion injuries; (3) match injuries for forwards and backs; (4) location of match injuries; (5) match event associated with injury. In addition, the mean/median days missed per match injury were extracted. Literature was excluded if appropriate injury incidence rate and either injury count or exposure time data were not reported or could not be obtained from the corresponding author. 'Elite' was defined as playing at international level, the top two leagues in a tier-one nation, or the top league in a tier-two nation. Duplicate records were identified and removed. Titles and abstracts of the remaining studies were assessed for relevance by SWi, CR and LS, with nonrelevant articles being discarded. All articles were screened by at least two reviewers. Full-text versions of the outstanding articles were then retrieved and evaluated against the inclusion criteria by two independent review groups ( $\mathrm{SWi}$ and CR, Cohen's kappa index value $=88.9 \%$; LS and SWe; Cohen's kappa index value $=93.6 \%$ ), with any conflicts resolved by KS $(n=16)$. 


\subsection{Assessment of Reporting Quality and Risk of Bias}

The reporting quality of included studies was evaluated by two independent reviewers ( $\mathrm{SWi}$ and $\mathrm{CR}$ ) using the 'Strengthening the Reporting of Observational Studies in Epidemiology' (STROBE) Sports Injury and Illness Surveillance (-SIIS) statement [13]. This 23-item checklist provides guidance on the reporting of observational studies on injury and illness in sports, but was not intended as a direct assessment of study quality. Discrepancies were resolved via discussion. The risk of small study bias was examined visually through funnel plots [available in the Online Supplementary Material (OSM)].

\subsection{Data Extraction}

For studies meeting the inclusion criteria, information pertaining to the level of play, study setting, surveillance period, number of injury events, mean/median days missed per injury, and exposure time was extracted. Where only two of injury count, injury incidence rate or exposure data were provided, the missing component was calculated using the available data (e.g., where injury count and injury incidence rate data were provided, the exposure time was calculated as: 'injury count/injury incidence rate $\times 1000$ '). Note, this approach may result in small rounding errors, but these have a negligible impact on the reported outcomes. Where relevant, multiple rows of data were extracted for each study to allow for the various combinations of counts and exposures required for each fixed effect (i.e., match injuries, training injuries, concussion injuries, body location, match event, and playing position (forwards/backs)). Data pertaining to seasons prior to 2012 were not extracted $[8,14,15]$.

World Rugby organises its member unions into six tiers according to playing strength and potential [16]: Tier-one teams participate in the Six Nations Championship (England, France, Ireland, Italy, Scotland and Wales) or The Rugby Championship (Argentina, Australia, New Zealand and South Africa) while tier two currently consists of Canada, USA, Uruguay, Georgia, Portugal, Romania, Russia, Spain, Namibia, Fiji, Samoa and Tonga. For 'level of play', club teams were considered to be 'level one' if they played in the highest league within a tier-one ranked nation, and 'level two' if they played in the second tier of a tier-one ranked nation, or in the highest league within a tier-two ranked nation [5]. Data from international teams and tournaments (e.g., Rugby World Cups) were categorised as 'international'. International Under-20 rugby tournaments [14] were categorised as 'level two'. Where required, authors were contacted to obtain any additional data that were not available in the full text versions; this was necessary for two of the included studies. Where multiple studies captured the same study period for a given team, preference was given to the study with the greatest overall exposure and/or via liaison with the original authors.

\subsection{Analysis and Interpretation of Results}

Statistical modelling was performed using the metafor package [17] in $R$ (version 4.0.2, R Foundation for Statistical Computing, Vienna, Austria). Incidence rate data were modelled using a mixed effects Poisson regression model. The response variable was the number of observed injuries, offset by the log of the number of exposure hours. Injury location and match-event incidence-rate data were summarised as a proportion of all injuries in the given individual study, and then analysed via a random-effects model with raw proportions [17]. Days missed data were modelled using a general linear mixed model [17]. Between-study heterogeneity was assessed with the $I^{2}$ statistic, where values of $25 \%, 50 \%$ and $75 \%$ represented low, moderate and high levels, respectively [18]. There were high levels of heterogeneity in all injury outcomes reported, and thus a random-effects term was included to allow for residual heterogeneity among studies and to account for the correlation arising from using multiple rows of data from the same study. Comparisons between playing levels and positional groups (forwards vs. backs) were made by including these variables as fixed effects. For the analysis of playing position, total exposure time was multiplied by 0.53 and 0.47 for forwards and backs, respectively, to account for the relative playing exposure for these positional groups (i.e., eight forwards and seven backs per team). All estimates are presented with $95 \%$ confidence intervals (CIs), with significance set at an alpha level of 0.05 .

\section{Results}

The electronic searches returned 2952 results. After removing duplicate and non-relevant records, 96 potentially relevant studies were assessed for inclusion in this review (Fig. 1). Nineteen prospective cohort studies were included in the final analysis, encompassing a total of 8819 match injuries and 2801 training injuries. The mean \pm SD reporting quality, as assessed by the 23-item STROBE-SIIS (Strengthening the Reporting of Observational studies in Epidemiology-Sports Injury and Illness Surveillance extension) checklist, was $17 \pm 3$ with a range of 9-21 (Table 1). Each individual rating for the STROBE-SIIS items is available in the OSM. Visual inspection of the funnel plots did not reveal any evidence of publication bias (see OSM). 


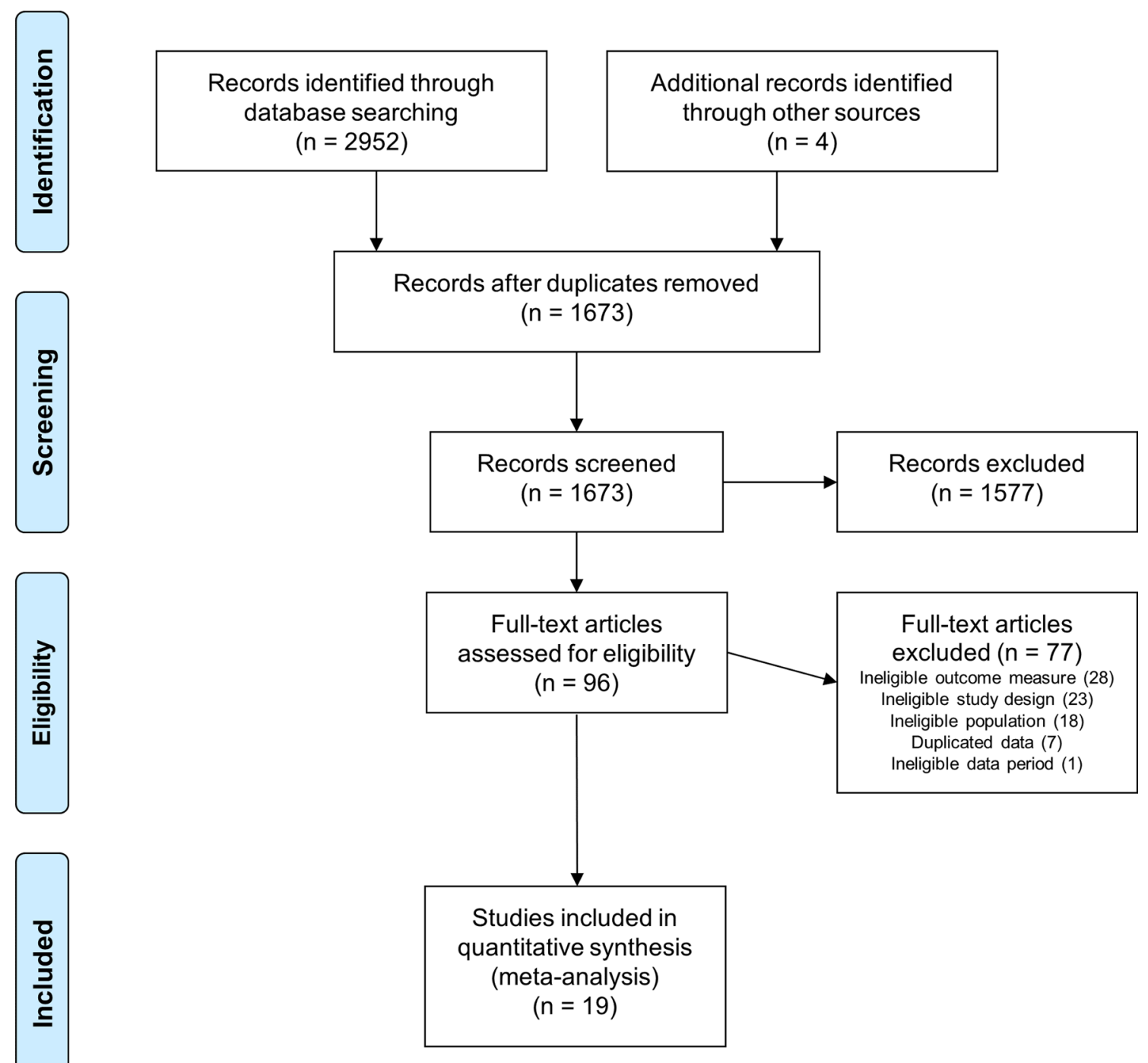

Fig. 1 PRISMA flow diagram of the study selection process

\subsection{Match Injury Incidence Rate}

Seventeen studies $[7,14,15,19,21-33]$ provided injury surveillance data for match injuries that could be included in the meta-analysis. The 17 studies reported a total of 8819 injuries amongst elite senior male Rugby Union players exposed to $101,694 \mathrm{~h}$ of match time. This yielded an overall injury incidence rate of 91 per $1000 \mathrm{~h}(95 \%$ CI 77-106). Level of play was not a significant moderator of this relationship $(P=0.37)$. The mean match incidence rates per $1000 \mathrm{~h}$ with $95 \% \mathrm{CI}$ were, in descending order: international: 109 (95\% CI 81-147); level one: 87 (95\% CI 79-96); and level two: 84 (56-125) (see Fig. 2).

\subsection{Days Missed per Injury}

Twelve studies [14, 15, 19, 22-25, 29-33] provided mean days missed data for match injuries that could be included in the general linear mixed model (see Fig. 3). The estimated mean days missed per match injury was 27 days (95\% CI 23-32), with no significant difference across playing levels $(P=0.87)$. Nine studies $[14,15,19,23,24,28$, 30-32] provided median days missed data for match injuries. The estimated median days missed per match injury was 8 days (95\% CI 4-11), with no significant difference across playing levels $(P=0.87)$. 


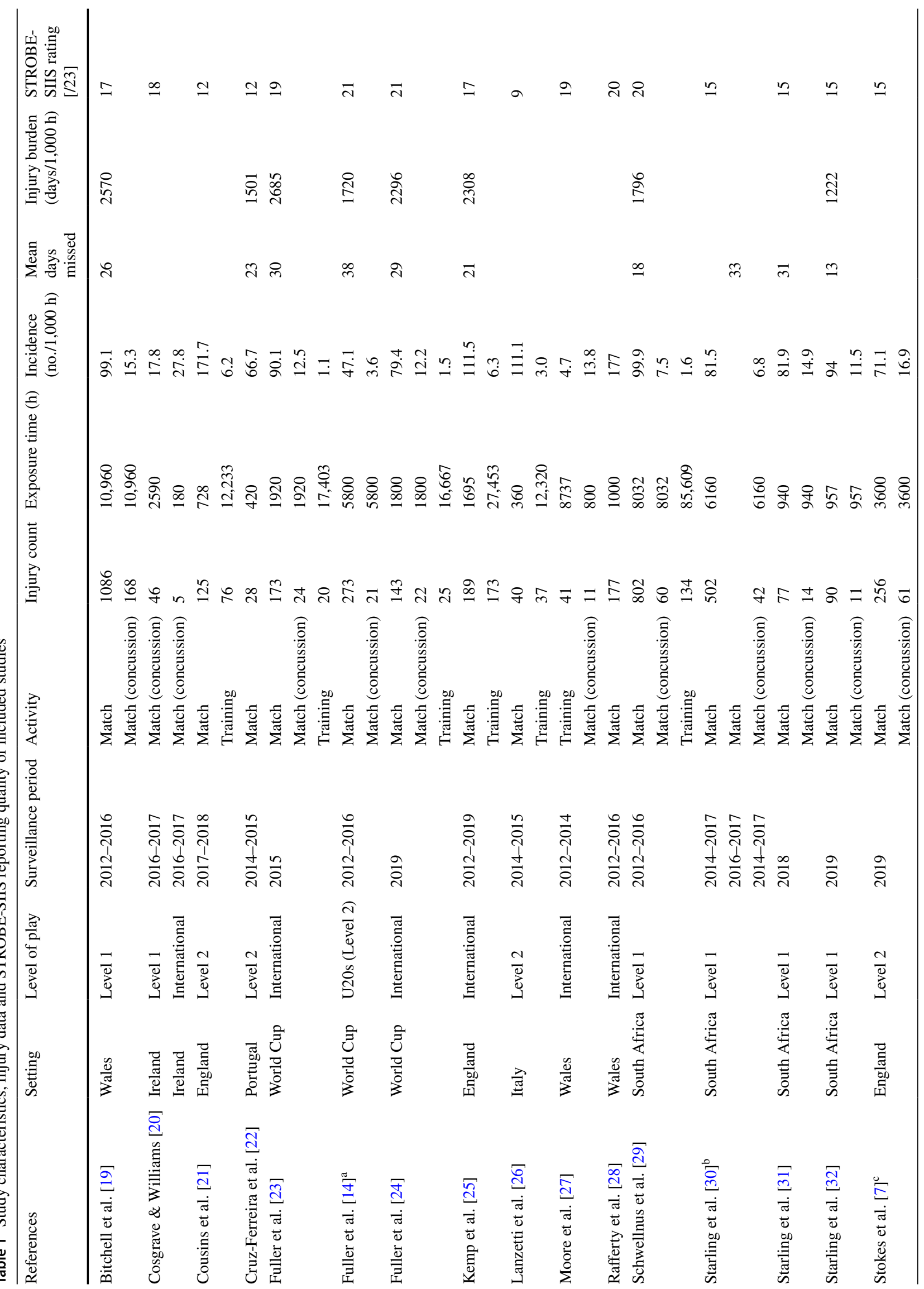




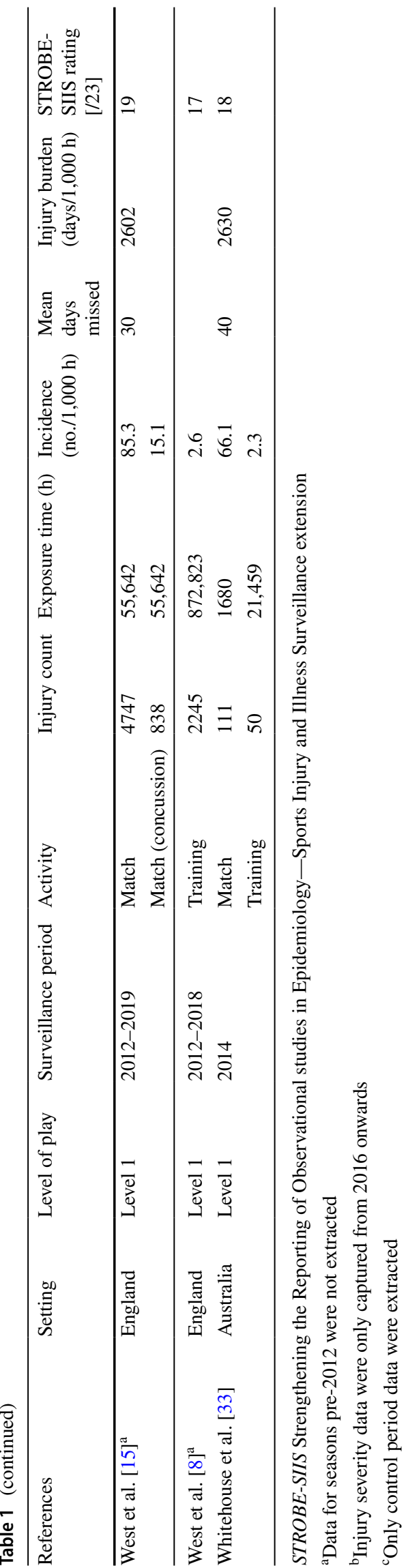

\subsection{Concussion}

Twelve studies $[7,14,15,19,20,23,24,27,29-32]$ provided match concussion incidence rate data that could be included in the meta-analysis (Fig. 4). The 12 studies encompassed a total of 1323 concussion injuries amongst elite senior male Rugby Union players exposed to $99,381 \mathrm{~h}$ of match time. The overall rate of match concussions was 12 per 1000 h (95\% CI 9-15), with no significant moderating effect of playing level $(P=0.39)$.

\subsection{Match Injury Locations}

For each injury location, a range of between four to ten studies provided data that could be included in the metaanalysis (Table 2). During matches, the head (16.7\%), knee $(12.9 \%)$ and shoulder (11.7\%) were the most common injury locations.

\subsection{Match Injury Events}

For each match injury event, a range of between six and nine studies provided data that could be included in the meta-analysis (Table 3). During matches, making tackles (23.0\%), being tackled (22.8\%), and collisions (14.2\%) were the most common injury events.

\subsection{Playing Position}

Eleven studies [14, 15, 19, 22-24, 29-33] that reported match-injury incidence rates for both forwards and backs were combined in the pooled analysis. The overall match-injury incidence rate was not significantly different $(P=0.95)$ between forwards $(78$ per $1000 \mathrm{~h} ; 95 \% \mathrm{CI}$ 66-91) and backs (76 per 1000 h; 95\% CI 60-97). Nine studies [14, 15, 19, 22-24, 31-33] also provided mean days missed data for these grouped playing positions that could be included in the general linear mixed model. The mean days missed per injury was significantly higher in forwards (31 days) versus backs (27 days, meta-analysed difference $=4$ days; $95 \%$ CI $3-5 ; P<0.001)$.

\subsection{Training Injury Incidence Rates}

Nine studies [8, 21, 23-27, 29, 33] provided injury surveillance data for training injuries that could be included in the meta-analysis (Fig. 5). The nine studies encompassed a total of 2801 injuries amongst elite senior male Rugby Union players exposed to $1,074,704 \mathrm{~h}$ of training time. The overall incidence of injuries in senior men's elite rugby training was 2.8 per 1000 h (95\% CI 1.9-4.0). Level of 
play was not a significant moderator of this relationship $(P=0.31)$.

\section{Discussion}

The current study presents an updated (2012-2020) overview of injury data in elite senior men's Rugby Union. This work represents the largest analysis of injuries in this setting to date, encompassing a total of 11,620 injuries. The overall match and training incidence rates in the present analysis were comparable to the 2013 meta-analysis [5]. These data confirm that the injury incidence rate for match injuries in elite senior men's Rugby Union is amongst the highest of all team sports, though the training injury incidence rate compares favourably $[34,35]$. The incidence rate for match concussion injuries is relatively high, and primary and secondary preventative efforts are a priority for this setting. The tackle accounts for the majority of match injury events and should continue to be the focus of future preventative efforts.

The overall meta-analysed match injury incidence rate was 91 per $1000 \mathrm{~h}$ (95\% CI 77-106), with no significant moderating effect of playing level. The 2013 meta-analysis reported substantial differences between playing levels, primarily driven by a significantly lower incidence rate in the level two setting (35 per $1000 \mathrm{~h}$ ) [5] in comparison to the current study ( 84 per $1000 \mathrm{~h}$ ). These findings may reflect improved reporting of injuries in level two settings, and greater homogeneity in medical support between playing levels. The injury incidence rates in level one club (87 per $1000 \mathrm{~h}$ ) and international (109 per $1000 \mathrm{~h}$ ) settings in the current meta-analysis were equivalent to the values reported in the 2013 meta-analysis ( 89 and 123 per $1000 \mathrm{~h}$, respectively) [5]. It should be noted that data relating to international teams were typically collected in a tournament setting (e.g., World Cups), which may be inherently different to matches played throughout seasonal club competitions due to differences in match scheduling, reporting practices, and greater disparities in resources and playing abilities between teams.

There were no significant differences in the mean days missed due to injury between levels of play. The mean days missed per match injury in the present meta-analysis was 7 days higher than the 2013 meta-analysis ( 20 vs. 27 days) [5], although this difference was not statistically significant. A recent longitudinal analysis has, however, reported significant increases in the mean days missed per injury in level one clubs over the last 16 seasons [15]. Future research should incorporate mixed method approaches (both qualitative and quantitative) to further explore the mechanism behind the increasing mean days missed per injury in this setting.
The overall rate of match concussions was 12 per $1000 \mathrm{~h}$ (95\% CI 9-15), with no significant moderating effect of playing level. However, this meta-analysed rate does not portray the changes in concussion reporting over time. For instance, in the English Premiership concussion rates have risen from $\sim 5$ per $1000 \mathrm{~h}$ in 2011-2012 to $\sim 20$ per $1000 \mathrm{~h}$ in recent seasons [15]. The increase in concussion incidence rates is likely due to a number of factors: the introduction of processes to better identify and manage head impact events during matches [9], a lowering of the diagnostic threshold [36], increased awareness and education around concussions [36], and also a likely real change in concussion risk resulting from alterations to the demands/laws of the elite game (e.g., increased tackle frequency [3]). In many settings, concussion has emerged as the most common match injury [15], and this is supported by the head being the most common injury location in the current analysis $(17 \%$ of all match injuries). The concern about potential long-term problems (e.g., neurodegenerative diseases) associated with concussion and/or multiple head impacts is recognised by medical and lay populations [10], and therefore governing bodies should continue to develop and evaluate strategies to lower the risk of concussion in elite senior men's Rugby Union. This may include law changes [6] and limiting contact exposure in training [37].

The tackle remains the match event associated with the largest proportion of injuries, with a similar risk evident for the ball carrier and tackler (being tackled $=23 \%$, tackling $=23 \%)$. In the previous meta-analysis, being tackled ( $\sim 36 \%$ of all injuries) was associated with a substantially higher injury incidence rate than making tackles ( 23\% of all injuries) [5]. Potential preventative efforts related to the tackle event that are currently being trialled include more stringent sanctioning of illegal high-contact tackles and reducing the height of the tackle [7]. Future strategies may address deficiencies in tackling technique on the non-dominant side [38], and developing technical capacity to resist the effects of physical fatigue during the tackle [39]. Elsewhere, there is some evidence that the incidence of running injuries, which accounted for $10 \%$ of all match injuries, has decreased [15]. There may be further scope for risk reduction of running-related injuries through targeted injury-prevention programmes $[40,41]$. The proportion of injuries associated with the scrum (4\%) was lower than reported in the 2013 meta-analysis (9\%) [5], which may be related to the gamewide introduction of a 'PreBind' technique in 2013-2014 that was shown to reduce the biomechanical loading on players during scrum engagements [42]. This demonstrates how the full injury prevention cycle can be effectively applied in elite team sports [43]. However, it should be noted that changes to the number of scrum events per match across this period may also account for this decrease in scrum-related injuries [44]. 


\section{Level 2}

Stokes et al. [7] | England | 256

Lanzetti et al. [26] | Italy | 40

Fuller et al. [14] | World Cup | 273

Cruz-Ferreira et al. [22] | Portugal | 28

Cousins et al. [21] | England | 125

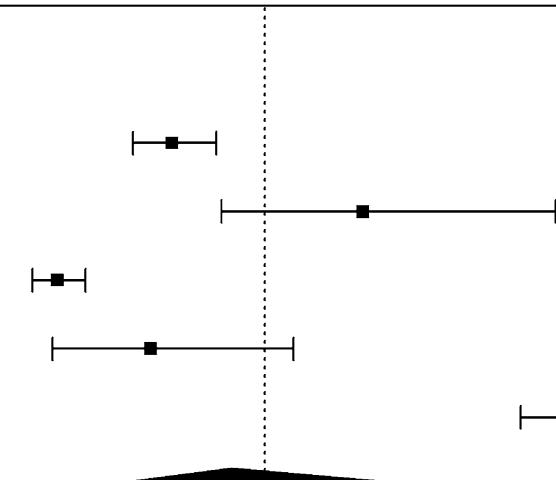

$71[63,80]$

$111[82,151]$

$47[42,53]$

$67[46,97]$

$172[144,205]$

$84[56,125]$

\section{Level 1}

Whitehouse et al. [33] | Australia | 111

West et al. [15] | England | 4747

Starling et al. [32] | South Africa | 90

Starling et al. [31] | South Africa | 77

Starling et al. [30] | South Africa | 502

Schwellnus et al. [29] | South Africa | 802

Bitchell et al. [19] | Wales | 1086

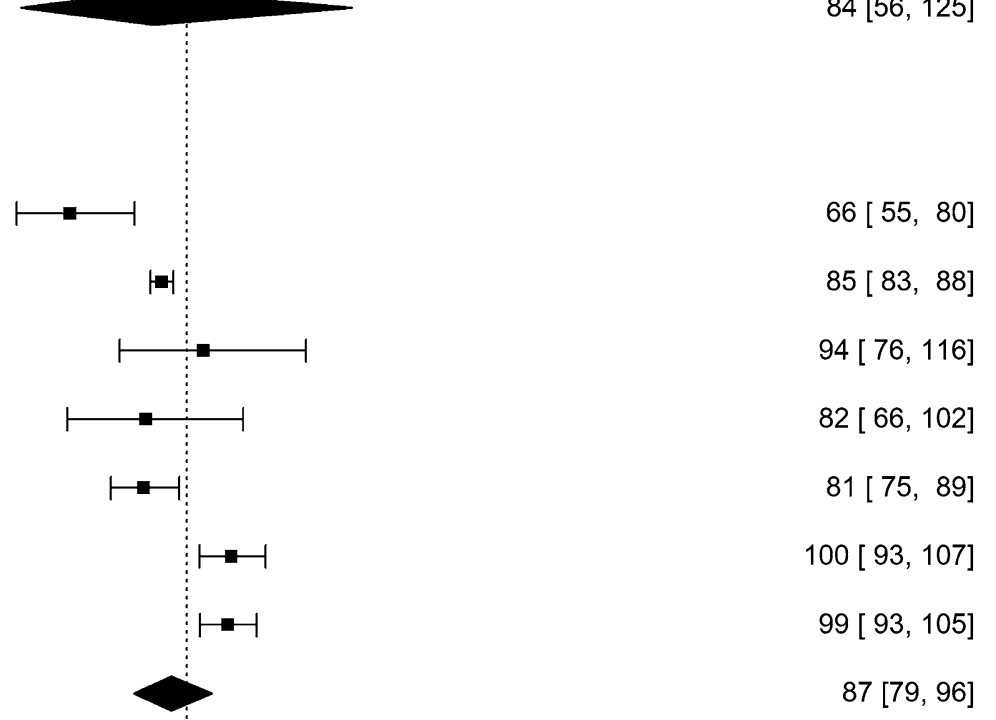

International

Rafferty et al. [28] | Wales | 177

Kemp et al. [25] | England | 189

Fuller et al. [24] | World Cup | 143

Fuller et al. [23] | World Cup | 173
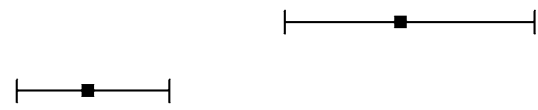

$177[153,205]$

$112[97,129]$

$79[67,94]$

$90[78,105]$

$109[81,147]$

RE Model for All Studies: $I^{2}=97.1 \% ; \tau^{2}=0.09$

Test for Subgroup Differences:

$Q_{M}=2.01, d f=2, p=0.3667$

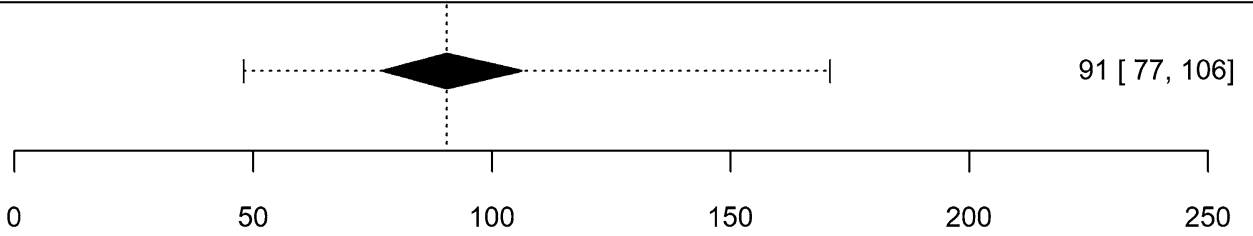

Match incidence rate (events per 1,000 match $\mathrm{h}$ )

Fig. 2 Incidence of match injuries (with 95\% confidence intervals) by level of play. Study reference, study setting and total number of injury events are provided for each study. The location of the diamond represents the estimated incidence rate and the width of the diamond reflects the precision of the estimate. The dashed line represents the prediction interval, which shows the range of the true effect in $95 \%$ of study settings 


\section{Level 2}

Fuller et al. [14] | World Cup | 273

Cruz-Ferreira et al. [22] | Portugal | 28

Level 1

Whitehouse et al. [33] | Australia | 111

West et al. [15] | England | 4747

Starling et al. [32] | South Africa | 90

Starling et al. [31] | South Africa | 77

Starling et al. [30] | South Africa | 268

Schwellnus et al. [29] | South Africa | 802

Bitchell et al. [19] | Wales | 1086

\section{International}

Kemp et al. [25] | England | 189

Fuller et al. [24] | World Cup | 143

Fuller et al. [23] | World Cup | 173

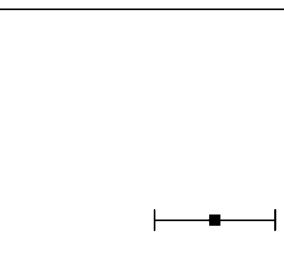

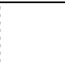
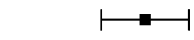

$38[35,41]$

$23[18,27]$

$30[15,45]$
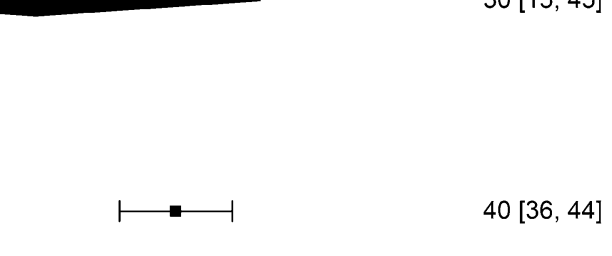

$H=-1$

$30[29,31]$

$13[11,15]$

$31[27,35]$

$33[30,36]$

$18[16,20]$

$26[24,28]$

$27[20,34]$

$21[18,23]$

$29[26,32]$

$30[27,33]$

$26[21,32]$

$27[23,32]$

$Q_{M}=0.27, d f=2, p=0.87$

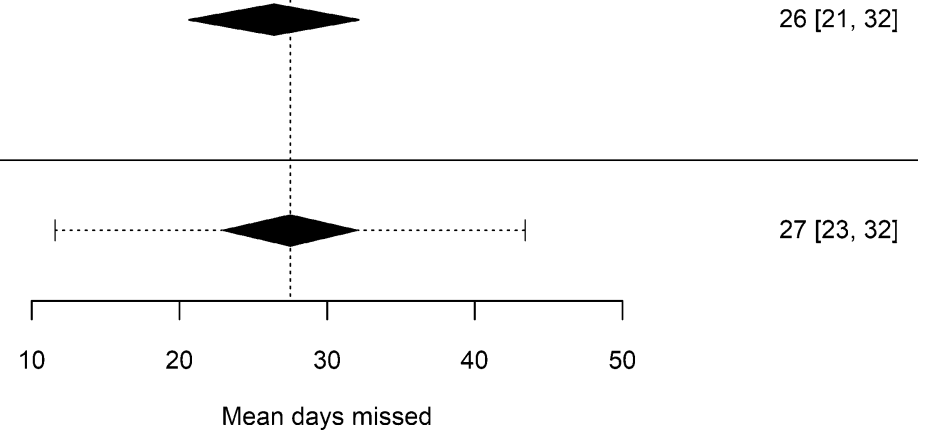

Fig. 3 Mean days missed for match injuries (with 95\% confidence intervals) by level of play. Study reference, study setting and total number of injury events are provided for each study. The location of the diamond represents the estimated mean days missed and the width of the diamond reflects the precision of the estimate. The dashed line represents the prediction interval, which shows the range of the true effect in $95 \%$ of study settings 


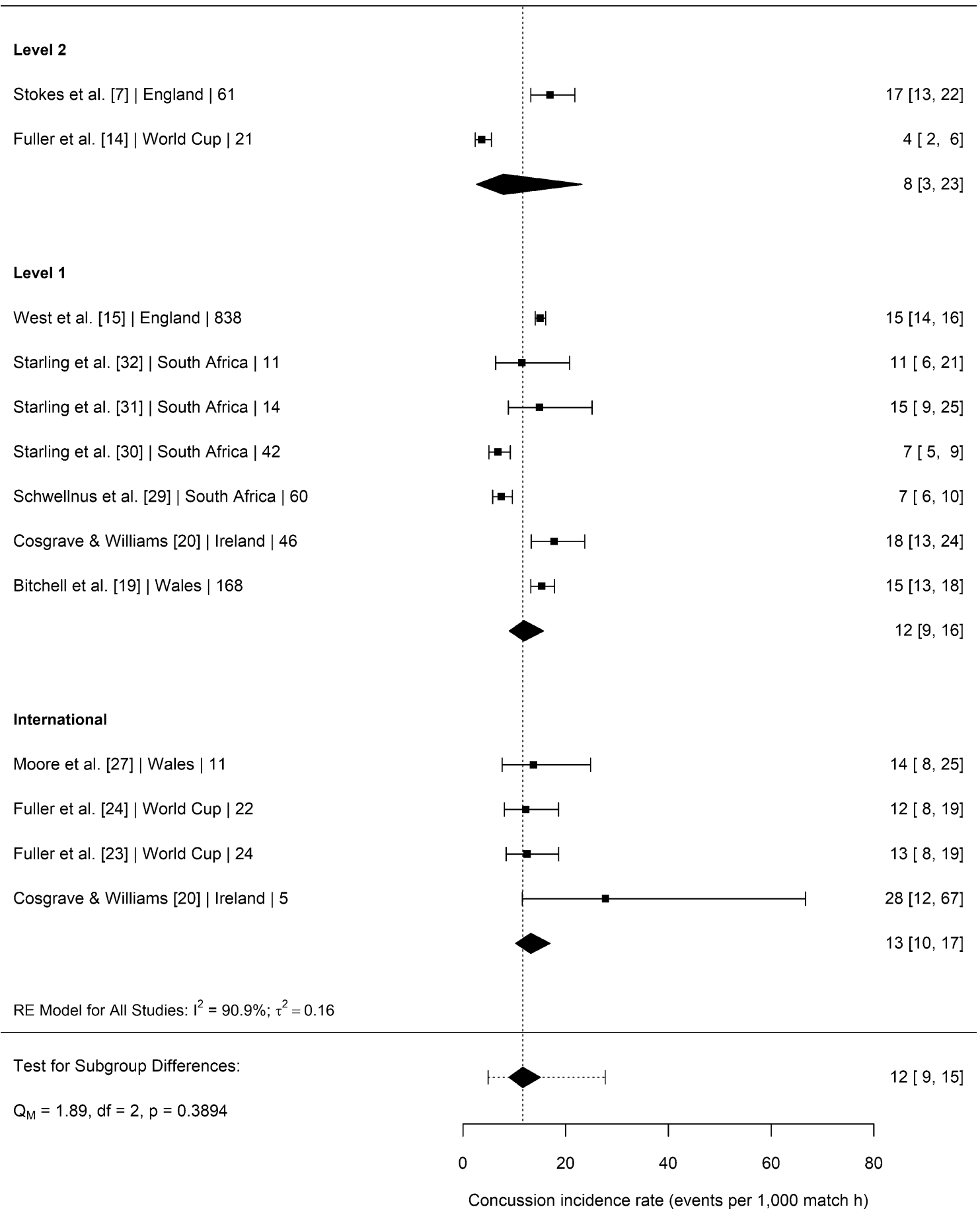

Fig. 4 Incidence of match concussion injuries (with 95\% confidence intervals) by level of play. Study reference, study setting and total number of injury events are provided for each study. The location of the diamond represents the estimated incidence rate and the width of the diamond reflects the precision of the estimate. The dashed line represents the prediction interval, which shows the range of the true effect in $95 \%$ of study settings 
Table 2 Match injuries as a function of injury location. Injury location incidence rate data were summarised as a proportion of all injuries in the given individual study; proportions from each study were then combined in the meta-analysis

\begin{tabular}{lllc}
\hline Injury location & $\begin{array}{l}\text { Number of } \\
\text { studies }\end{array}$ & $\begin{array}{l}\text { Total injury } \\
\text { count }\end{array}$ & $\begin{array}{l}\text { Meta-analysed pro- } \\
\text { portion (95\% CI) }\end{array}$ \\
\hline Head & 10 & 1439 & $16.7 \%(13.5-19.9)$ \\
Knee & 10 & 1034 & $12.9 \%(12.1-13.6)$ \\
Shoulder & 10 & 933 & $11.7 \%(9.6-13.8)$ \\
Ankle & 9 & 312 & $9.3 \%(7.9-10.7)$ \\
Posterior thigh & 8 & 447 & $6.5 \%(5.3-7.7)$ \\
Lower leg & 10 & 570 & $6.5 \%(5.5-7.5)$ \\
Anterior thigh & 8 & 338 & $6.0 \%(4.4-7.6)$ \\
Chest & 6 & 311 & $4.0 \%(1.9-6.1)$ \\
Hip/groin & 10 & 330 & $3.8 \%(2.6-5.1)$ \\
Wrist/hand & 10 & 177 & $3.6 \%(2.4-4.7)$ \\
Upper back & 4 & 28 & $3.1 \%(0.7-5.6)$ \\
Neck & 9 & 338 & $2.9 \%(1.7-4.1)$ \\
Foot & 9 & 84 & $2.4 \%(1.8-3.0)$ \\
Lower back & 10 & 161 & $1.8 \%(1.5-2.2)$ \\
Elbow & 7 & 33 & $1.2 \%(0.7-1.7)$ \\
Pelvis/sacrum & 4 & 22 & $1.2 \%(0.2-1.9)$ \\
Upper arm & 6 & 47 & $0.7 \%(0.5-0.9)$ \\
Abdomen & 4 & 38 & $0.7 \%(0.5-0.9)$ \\
Forearm & 6 & 49 & $0.7 \%(0.5-0.9)$ \\
\hline
\end{tabular}

The mean days missed per injury was significantly higher in forwards versus backs (meta-analysed difference $=4$ days, 95\% CI 3-5), though no differences in injury incidence rates were observed. The higher mean days missed per injury in forwards may be a result of their involvement in a higher frequency and number of collisions per match [45]. In particular, forwards are involved in more tackle and ruck events than backs, which are considered amongst the highest burden events and which have increased in frequency per match over recent seasons [15]. These positional demands directly influence the assessment of activity risk within the returnto-play decision framework following an injury [46], which may also account for the observed difference in the mean days missed per injury between forwards and backs. There are likely to be position-specific differences in match injury profiles, determined by the physical and technical requirements of each position, which may be used to design more targeted injury-prevention programmes [47]. These positionspecific injury profiles warrant an updated investigation, given the changes to game and positional demands that have occurred over recent seasons [3].

The overall meta-analysed training injury incidence rate in senior men's elite Rugby Union was 2.8 per 1000 h (95\% CI 1.9-4.0) with no significant moderating effect of playing level. This training injury incidence rate was equivalent to the rate reported in the 2013 meta-analysis ( 3 per $1000 \mathrm{~h}$;
Table 3 Match injuries as a function of match event. Match-event incidence-rate data were summarised as a proportion of all injuries in the given individual study; proportions from each study were then combined in the meta-analysis

\begin{tabular}{lllc}
\hline Match event & $\begin{array}{l}\text { Number of } \\
\text { studies }\end{array}$ & $\begin{array}{l}\text { Total injury } \\
\text { count }\end{array}$ & $\begin{array}{l}\text { Meta-analysed pro- } \\
\text { portion (95\% CI) }\end{array}$ \\
\hline Tackling & 9 & 1497 & $23.0 \%(20.7-25.2)$ \\
Tackled & 9 & 1633 & $22.8 \%(20.7-24.9)$ \\
Collision & 7 & 737 & $14.2 \%(10.2-18.2)$ \\
Running & 9 & 713 & $10.4 \%(7.5-13.3)$ \\
Ruck & 9 & 627 & $8.9 \%(6.8-11.0)$ \\
Scrum & 9 & 257 & $4.3 \%(3.1-5.4)$ \\
Maul & 5 & 131 & $2.2 \%(1.9-2.6)$ \\
Lineout & 5 & 77 & $1.3 \%(1.0-1.6)$ \\
Kicking & 6 & 30 & $0.6 \%(0.2-1.0)$ \\
\hline
\end{tabular}

95\% CI: $2-4)$ and compares favourably with rates reported in sports such as men's professional football (4 per $1000 \mathrm{~h}$ [35])

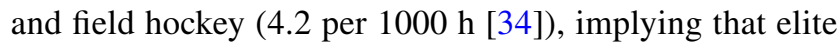
Rugby Union teams manage the risk associated with contact elements of training effectively. Despite the relatively low incidence rate of training injuries, they nonetheless occur in a largely controllable environment and represent a substantial proportion of all injury events (approximately one-third) [8]. Therefore, injury reduction strategies targeted at this aspect of the game have the potential to substantially reduce the overall burden of injury as well as improving career longevity of those players involved at the elite level of the game.

There may be some limitations affecting the outcomes of this meta-analysis. Injury surveillance data are reported across a range of sources, including websites, theses, conference abstracts, and stakeholder reports [48]. As such, it is possible that relevant surveillance data, both injury and exposure quantification, may have been missed. However, the extensive and systematic search strategy (including grey literature) used in the present meta-analysis is likely to have captured the vast majority of relevant data in elite senior men's Rugby Union. Whilst all included studies used a 24-h time-loss injury definition and followed the consensus statement for injury surveillance in Rugby Union [12], methodological differences between settings (i.e., differences in who records the injury data, how data are recorded [e.g., online vs. paper-based forms), and the study setting (e.g., short tournament vs. whole-season competition)] may influence the completeness and validity of the data [48]. Since all injury-report measures are likely to have some degree of error, true 'gold standard' sources rarely exist, and therefore quality assessment of injury surveillance studies is difficult to undertake [48]. Injury surveillance systems in elite senior men's Rugby Union should endeavour to assess and report the quality 


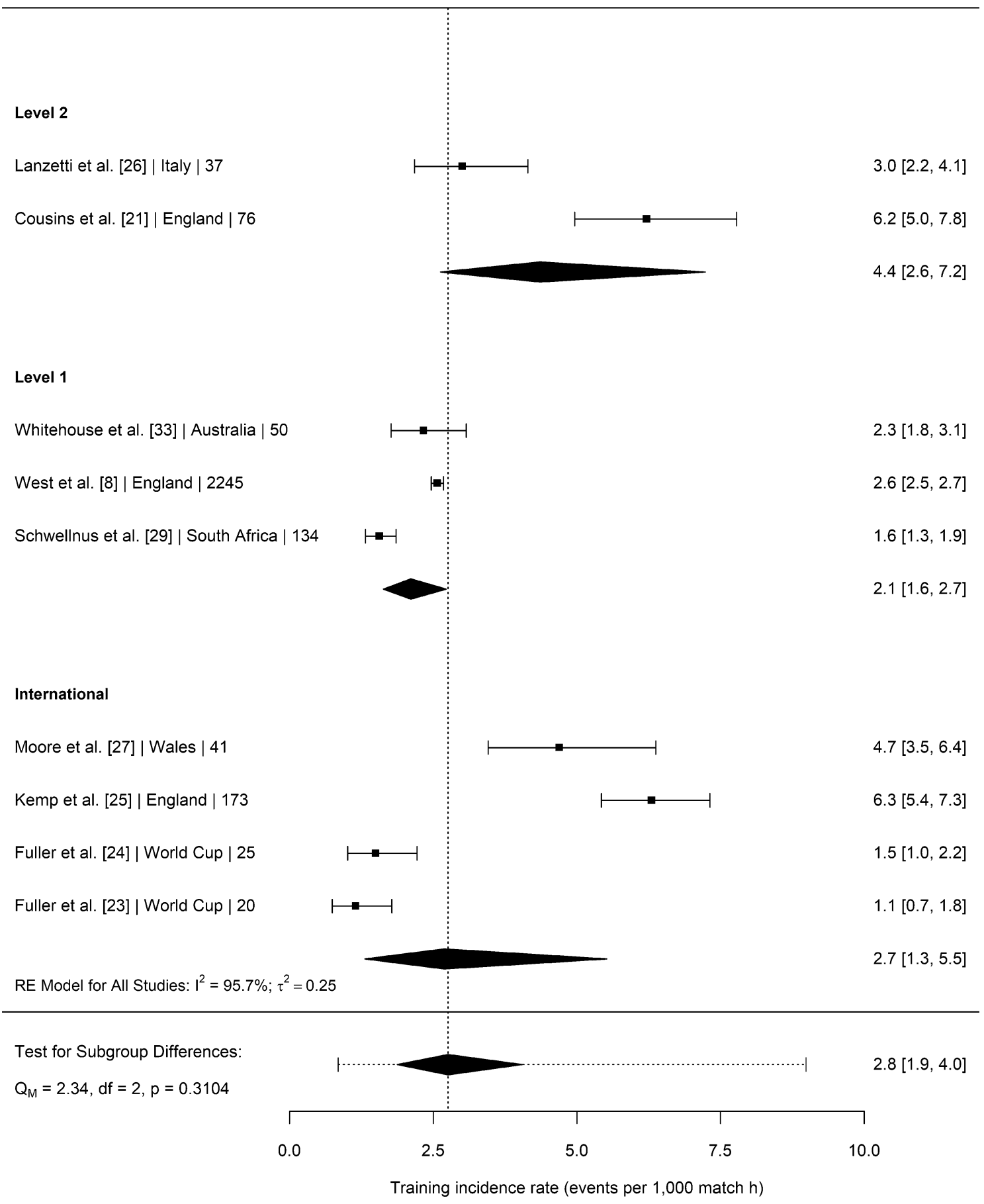

Fig. 5 Incidence of training injuries (with 95\% confidence intervals) by level of play. Study reference, study setting and total number of injury events are provided for each study. The location of the diamond represents the estimated incidence rate and the width of the

and completeness of their data in future publications $[13,49]$. For instance, the largest study in the present meta-analysis ( $n=4747$ injuries) was overseen by a lead diamond reflects the precision of the estimate. The dashed line represents the prediction interval, which shows the range of the true effect in $95 \%$ of study settings

researcher at the host institution, who implemented a quality control process to ensure all injury details were captured on a regular basis, and undertook a validation 
of reported match injuries using match report cards completed by match officials [15]. Finally, these data only relate to the elite men's game, and so are not generalisable to other Rugby Union populations.

\section{Conclusions}

The overall match and training injury incidence rates in senior men's elite Rugby Union were 91 per $1000 \mathrm{~h}$ and 2.8 per $1000 \mathrm{~h}$, respectively. Playing level did not significantly moderate any of the outcome measures. These data confirm that the injury incidence rate for match injuries in elite senior men's Rugby Union, and the rate of concussion/head injuries in particular, is amongst the highest of all team sports. The tackle accounts for the majority of these match injury events. Whilst the training injury incidence rate compared favourably with other team sports, injury-reduction strategies targeted at this aspect of the game have the potential to substantially reduce the overall burden of injury and improve career longevity of those players involved at the elite level of the game. Going forwards, primary and secondary preventative strategies for concussion injuries are a key priority for this setting, with the tackle event being the obvious point of focus for primary prevention efforts.

Supplementary Information The online version contains supplementary material available at https://doi.org/10.1007/s40279-021-01603-w.

\section{Declarations}

Funding No funding was received to conduct this study.

Conflict of Interest Sean Williams has received research grants from World Rugby and the Rugby Football Union in the recent past or currently. James Brown has received research grants, partial conference funding, and bursaries from World Rugby in the recent past or currently. Keith Stokes is employed by the Rugby Football Union. Charlotte Robertson, Lindsay Starling, Carly McKay, and Stephen West declare that they have no conflicts of interest relevant to the content of this review.

Authorship Contributions SWi conducted the literature search, data extraction, statistical analyses and wrote the first draft of the manuscript. CR and LS screened abstracts/titles. CR, LS, SWe, JB and KS assessed full-text articles for eligibility. SWi and CR assessed study reporting quality. All authors contributed with notable critical appraisal of the text and approved the final version.

Availability of Data and Material (Data Transparency) Open Science Framework at https://osf.io/z4xp7/files/

Code Availability (Software Application or Custom Code) https://osf. io/z4xp7/files/
Ethics Approval Not applicable.

Consent to Participate Not applicable.

Open Access This article is licensed under a Creative Commons Attribution 4.0 International License, which permits use, sharing, adaptation, distribution and reproduction in any medium or format, as long as you give appropriate credit to the original author(s) and the source, provide a link to the Creative Commons licence, and indicate if changes were made. The images or other third party material in this article are included in the article's Creative Commons licence, unless indicated otherwise in a credit line to the material. If material is not included in the article's Creative Commons licence and your intended use is not permitted by statutory regulation or exceeds the permitted use, you will need to obtain permission directly from the copyright holder. To view a copy of this licence, visit http://creativecommons.org/licenses/by/4.0/.

\section{References}

1. World Rugby. Player numbers. 2017. https://www.world.rugby/ development/player-numbers. Accessed 14 Dec 2020.

2. Cahill N, Lamb K, Worsfold P, et al. The movement characteristics of English Premiership rugby union players. J Sports Sci. 2013;31(3):229-37.

3. Kraak W, Coetzee F, Venter R. Analysis of the general match profile of international rugby union between 2007 and 2013. Int J Perform Anal Sport. 2017;17(3):303-18.

4. Quarrie KL, Hopkins WG. Changes in player characteristics and match activities in Bledisloe Cup rugby union from 1972 to 2004. J Sports Sci. 2007;25(8):895-903.

5. Williams S, Trewartha G, Kemp S, et al. A meta-analysis of injuries in senior men's professional Rugby Union. Sports Med. 2013;43(10):1043-55.

6. Raftery M, Tucker R, Falvey ÉC. Getting tough on concussion: how welfare-driven law change may improve player safety-a Rugby Union experience. Br J Sports Med. 2021;55:527-9.

7. Stokes KA, Locke D, Roberts S, et al. Does reducing the height of the tackle through law change in elite men's rugby union (The Championship, England) reduce the incidence of concussion? A controlled study in 126 games. Br J Sports Med. 2021;55:220-5.

8. West SW, Williams S, Kemp SPT, et al. Patterns of training volume and injury risk in elite rugby union: an analysis of 1.5 million hours of training exposure over eleven seasons. J Sports Sci. 2020;38(3):238-47.

9. Fuller G, Tucker R, Starling L, et al. The performance of the World Rugby Head Injury Assessment Screening Tool: A diagnostic accuracy study. Sports Med Open. 2020;6(1):2.

10. Schneider DK, Grandhi RK, Bansal P, et al. Current state of concussion prevention strategies: A systematic review and metaanalysis of prospective, controlled studies. Br J Sports Med. 2017;51(20):1473-82.

11. Stroup D, Berlin J, Morton S, et al. MOOSE guidelines for metaanalyses and systematic reviews of observational studies. J Am Med Assoc. 2000;283(15):2008-12.

12. Fuller CW, Molloy MG, Bagate $\mathrm{C}$, et al. Consensus statement on injury definitions and data collection procedures for studies of injuries in rugby union. Br J Sports Med. 2007;41(5):328-31.

13. Bahr R, Clarsen B, Derman W, et al. International Olympic Committee consensus statement: methods for recording and reporting of epidemiological data on injury and illness in sport 2020 
(including STROBE Extension for Sport Injury and llness Surveillance (STROBE-SIIS)). Br J Sports Med. 2020;54:372-89.

14. Fuller CW, Taylor A, Raftery M. Eight-season epidemiological study of injuries in men's international Under-20 rugby tournaments. J Sports Sci. 2018;36(15):1776-83.

15. West S, Starling L, Kemp SP, et al. Trends in match injury risk in professional male rugby union-a 16-season review of 10851 match injuries in the English Premiership (2002-2019): The Professional Rugby Injury Surveillance Project. Br J Sports Med. 2020. https://doi.org/10.1136/bjsports-2020-102529.

16. World Rugby. IRB Strategic Plan. 2014. http://resources.world. rugby/worldrugby/document/2014/11/12/846ce431-bed4-498083d0-b8a6d035dfe0/041207IRBStrategicPlan_772.pdf. Accessed 14 Sep 2020.

17. Viechtbauer W. Conducting meta-analyses in $\mathrm{R}$ with the metafor package. J Stat Softw. 2010;36(3):1-48.

18. Higgins JP, Thompson SG, Deeks JJ, et al. Measuring inconsistency in meta-analyses. BMJ. 2003;327(7414):557-60.

19. Bitchell CL, Mathema P, Moore IS. Four-year match injury surveillance in male Welsh professional Rugby Union teams. Phys Ther Sport. 2020;42:26-32.

20. Cosgrave M, Williams S. The epidemiology of concussion in professional rugby union in Ireland. Phys Ther Sport. 2019;35:99-105.

21. Cousins BEW, Morris JG, Sunderland C, et al. Match and training load exposure and time-loss incidence in elite Rugby Union players. Front Physiol. 2019;10(1413):1-11.

22. Cruz-Ferreira AM, Cruz-Ferreira EM, Ribeiro PB, et al. Epidemiology of time-loss injuries in senior and under-18 Portuguese male rugby players. J Hum Kinet. 2018;62(1):73-80.

23. Fuller CW, Taylor A, Kemp SPT, et al. Rugby World Cup 2015: World Rugby injury surveillance study. Br J Sports Med. 2017;51(1):51-7.

24. Fuller C, Taylor A, Douglas M, et al. Rugby World Cup 2019 injury surveillance study. S Afr J Sports Med. 2020;32(1):1-6.

25. Kemp SPT, West S, Antstiss T, et al. England Professional Rugby Injury Surveillance Report: Season Report 2018-19. 2020.

26. Lanzetti RM, Lupariello D, Venditto T, et al. The influence of playing surface on injury risk in Italian elite rugby players. Muscles Ligaments Tendons J. 2017;7(1):180-5.

27. Moore IS, Ranson C, Mathema P. Injury risk in international rugby union three-year injury surveillance of the Welsh national team. Orthop Sports Med. 2015;3(7).

28. Rafferty J, Ranson C, Oatley G, et al. On average, a professional rugby union player is more likely than not to sustain a concussion after 25 matches. Br J Sports Med. 2019;53(15):969-73.

29. Schwellnus MP, Jordaan E, Van Rensburg CJ, et al. Match injury incidence during the Super Rugby tournament is high: a prospective cohort study over five seasons involving 93641 player-hours. Br J Sports Med. 2019;53(10):620-7.

30. Starling L, Readhead C, Viljoen W, et al. The Currie Cup Premiership Competition Injury Surveillance Report 2014-2017. S Afr J Sports Med. 2018;30(1):1-42.

31. Starling L, Readhead C, Viljoen W, et al. The Currie Cup Premiership Competition Injury Surveillance Report 2014-2018. S Afr J Sports Med. 2019;31(1):1-47.

32. Starling L, Readhead C, Viljoen W, et al. SA Rugby Injury and Illness Surveillance and Prevention Project (SARIISPP) The Currie Cup Premiership Competition Injury Surveillance Report 2019. S Afr J Sports Med. 2020;32(1):1-13.

33. Whitehouse T, Orr R, Fitzgerald E, et al. The epidemiology of injuries in Australian professional rugby union 2014 Super Rugby competition. Orthop Sports Med. 2016;4(3).
34. Rees H, Mccarthy Persson U, Delahunt E, et al. Epidemiology of injuries in senior men's field hockey: a two-season prospective observational injury surveillance study. J Sports Sci. 2020;38(24):2842-9.

35. Hägglund $\mathbf{M}$, Waldén $M$, Magnusson $H$, et al. Injuries affect team performance negatively in professional football: An 11-year follow-up of the UEFA Champions League injury study. Br J Sports Med. 2013;47(12):738-42.

36. Cross M, Trewartha G, Kemp S, et al. Concussion in rugby Union: improved reporting, a more conservative approach or an increased risk? Br J Sports Med. 2017;51(4):309.

37. Mccrea MA, Shah A, Duma S, et al. Opportunities for prevention of concussion and repetitive head impact exposure in college football players: A Concussion Assessment, Research, and Education (CARE) Consortium study. JAMA Neurol. 2021;78(3):346-50.

38. Seminati E, Cazzola D, Preatoni E, et al. Tackle direction and dominant side affect upper body loading during rugby tackles. $\mathrm{Br}$ J Sports Med. 2017;51(4):386.

39. Davidow D, Redman M, Lambert M, et al. The effect of physical fatigue on tackling technique in Rugby Union. J Sci Med Sport. 2020;23(11):1105-10.

40. Attwood MJ, Roberts SP, Trewartha G, et al. Efficacy of a movement control injury prevention programme in adult men's community rugby union: a cluster randomised controlled trial. Br J Sports Med. 2018;52(6):368-74.

41. Al Attar WSA, Soomro N, Sinclair PJ, et al. Effect of injury prevention programs that include the nordic hamstring exercise on hamstring injury rates in soccer players: a systematic review and meta-analysis. Sports Med. 2017;47(5):907-16.

42. Cazzola D, Preatoni E, Stokes KA, et al. A modified prebind engagement process reduces biomechanical loading on front row players during scrummaging: a cross-sectional study of 11 elite teams. Br J Sports Med. 2015;49(8):541-6.

43. O'Brien J, Finch CF, Pruna R, et al. A new model for injury prevention in team sports: the Team-sport Injury Prevention (TIP) cycle. Sci Med Football. 2019;3(1):77-80.

44. World Rugby. World Rugby game analysis reports. 2019. https:// www.playerwelfare. worldrugby.org/?documentid=156. Accessed 28 May 2021.

45. Macleod SJ, Hagan C, Egaña M, et al. The use of microtechnology to monitor collision performance in professional rugby union. Int J Sports Physiol Perform. 2018;13(8):1075-82.

46. Shrier I. Strategic Assessment of Risk and Risk Tolerance (StARRT) framework for return-to-play decision-making. Br J Sports Med. 2015;49(20):1311-5.

47. Brooks JH, Kemp S. Injury-prevention priorities according to playing position in professional rugby union players. Br J Sports Med. 2011;45(10):765-75.

48. Ekegren CL, Gabbe BJ, Finch CF. Sports injury surveillance systems: a review of methods and data quality. Sports Med. 2016;46(1):49-65.

49. Kucera KL, Marshall SW, Bell DR, et al. Validity of soccer injury data from the National collegiate athletic association's injury surveillance system. J Athl Train. 2011;46(5):489-99. 